\title{
Characteristics of the extreme warm and cold days over Greece
}

\author{
M. S. Varfi, T. S. Karacostas, T. J. Makrogiannis, and A. A. Flocas \\ Department of Meteorology and Climatology, Aristotle University of Thessaloniki, Greece \\ Received: 22 December 2008 - Revised: 31 March 2009 - Accepted: 5 April 2009 - Published: 7 April 2009
}

\begin{abstract}
An attempt is made to study the characteristics of the extreme warm and cold days over the major area of Greece. To meet this objective, the daily maximum and minimum air temperature values are used, obtained from seventeen (17) synoptic weather stations, covering the broad study area. The extreme warm and cold days are identified based upon the proposed and adopted criteria, which are applied for the period 1961-2000. Seven regional decadal indices measuring the frequency of occurrence, the magnitude and the intensity of the extreme temperature values are calculated. The study of the indices revealed that after the 70' the frequency of occurrence and the intensity of cold days follow a negative trend, as opposed to the frequency of occurrence and the intensity of the warm days that follow a positive trend. Moreover, the proposed indices confirm the cooling conditions that Greece experienced in the 70's and early 80's and the warming trend afterwards.
\end{abstract}

\section{Introduction}

The study of the extreme weather events has received a great emphasis worldwide, as their effects and consequences are encountered to many disciplines, incorporating atmosphere, biosphere and even economy (Chan et al., 2005; Chagnon et al., 2003). According to Rusticucci and Vargas (2002), the two parameters that mostly affect the human being and their living activities, are the extreme daily temperature values and their persistence, as well.

Now a day, a great concern should be focused on the wellindicated climatic changes, which are mostly documented through the air temperature and particularly on the influences due to the intensity, frequency of occurrence, duration and severity of the extreme temperature events. Many recent studies revealed changes in the climatic characteristics of the temperature extremes in a global and regional scale and the development of several indicators as useful tool to study upon (Alexander et al., 2006; Tank and Können, 2003; Moberg and Jones, 2005; Della-Marta et al., 2007a).

The objective on this study is to clarify whether the frequency of occurrence, the magnitude and the intensity of the extreme air temperature events (warm and cold) in Greece have changed during the four last decades of the 20th century. This is accomplished through the development of regional decadal indices, appropriate to calculate the frequency of occurrence, the magnitude and the intensity of the extreme air temperature events and to suitably prescribe, in a general sense, the overall picture and trend of the air temperature regime over the major area of Greece.

\section{Data analyses and methodology}

\subsection{Air temperature time series}

The data used in this study consist of valid and reliable measurements of max and min daily air temperature records from seventeen (17) synoptic weather stations that cover the entire Greek area (Fig. 1), for the chronological period 19612000. The air temperature time series were obtained from the Hellenic National Meteorological Service. Essential data quality control was carried out using logic tests in order to complete missing information and correct outliers and invalid data. The Alexandersson test (Alexandersson, 1986) was firstly applied to examine the homogeneity of the temperature data records. The null hypothesis of the inhomogeneity of the time series was rejected.

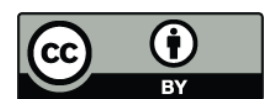

Correspondence to: M. S. Varfi

(varfi@geo.auth.gr)

Published by Copernicus Publications on behalf of the European Geosciences Union. 


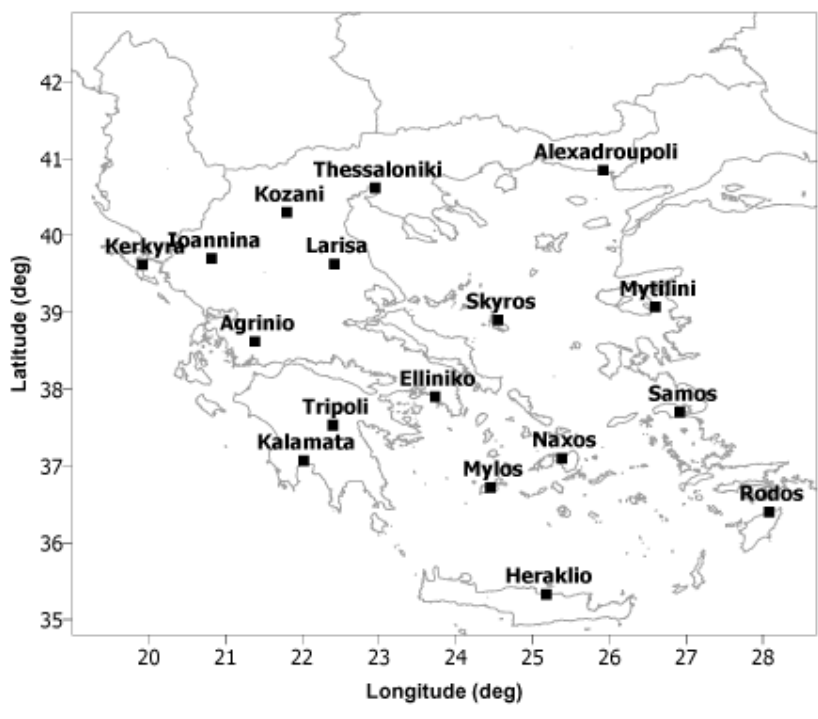

Fig. 1. Map of Greece, showing the 17 stations used in the study.

\subsection{Definition}

The criteria adopted for the identification of the extreme warm and cold days rely upon a straight and direct comparison between the daily maximum and minimum temperatures against the analogous average daily maximum and minimum temperature values, which were calculated and represent the mean calendar climatological year of the whole examined period. The 1.5 standard deviations on either side of the average value were used as the threshold value. More specifically:

1, Extreme warm day at a station is the day at which the daily maximum temperature satisfies the Relation (1):

$T_{\text {max daily }} \geq T_{\text {mean max daily }}+1.5 s d_{\text {maxdaily }}$

2. Extreme cold day at a station is the day at which the daily minimum temperature satisfies the Relation (2):

$T_{\text {min daily }} \leq T_{\text {mean min daily }}-1.5 \mathrm{~s} d_{\text {min daily }}$

where, $T_{\max \text { daily }}$ and $T_{\min \text { daily }}$ are the daily $\max$ and $\min$ temperatures for every calendar day of the studied period, $T_{\text {mean max daily }}$ and $T_{\text {mean min daily }}$ are the mean max and min temperature for every calendar day for the whole study period and $s d_{\text {max daily }}$ and $s d_{\text {min daily }}$ are the corresponding standard deviations.

The adopted criterion, which somehow resembles the one used by Burgueno et al. (2002), is considered reliable and practical, due to the following reasons: (a) the deviations where taken from the daily, and not from the monthly mean values, eliminating thus the incorporated variability and (b) the coefficient of 1.5 standard deviations around the mean was chosen - in such a way - to take into consideration, roughly, the 6-7\% of the total number of days, demonstrating thus the extremity of the adopted criteria.
Particular effort was given to the use of the daily temperature values (average and extremes) for the identification of the extreme warm and cold days. It is believed, that this way, any undesirable systematic bias is avoided, since all the data information are taken into consideration, for the establishment of the initial definitions-criteria and the furthermore calculations, as well. Moreover, recent studies, (Feidas et al., 2004), over the area of interest, do not indicate any consistent and obvious trend, neither on the annual, nor on any seasonal, sense.

\subsection{Methodology}

Extreme warm and cold days are identified and selected for each station and for the 40-year period (1961-2000), using the aforementioned criteria for the warm (April-September) and cold (October-March) periods of the year. The choice of the warm and cold periods was somehow arbitrary, however well consistent with the local literature (Cartalis et al., 2004; Mazarakis et al., 2008).

To assess the magnitude of the extreme daily temperature values, the anomalies of the warm and cold days from the thresholds values, are calculated. This amount could be a good indication of the temperature regime and hence a sign of a possible warming or cooling in the specific studied area. The absolute anomalies of the warm and cold days are named temperature surplus and temperature deficit, respectively. So, the temperature surplus of a warm day is defined as the difference of the threshold value from the maximum daily temperature:

$T_{\max \text { daily }}-\left(T_{\text {mean max daily }}+1.5 s d_{\max \text { daily }}\right)$

In a similar way, the temperature deficit of a cold day is defined as the difference of the minimum daily temperature from the threshold value:

$\left(T_{\text {mean min daily }}-1.5 s d_{\min \text { daily }}\right)-T_{\min \text { daily }}$

For every studied period, all the "warm days surplus" and the "cold days deficit" are added together per year, giving thus the annual indices of the cumulative temperature surplus and the cumulative temperature deficit, respectively, for each one station.

In order to have an overall cooling or warming criterion, the "cumulative temperature rest" is defined as the difference between the cumulative temperature surplus and the cumulative temperature deficit. The "cumulative temperature rest" was annually calculated for every station.

Two more indices, measuring the intensity of warm and cold days, namely Surwar (cumulative temperature surplus/frequency of occurrence of warm days) and Defcol (cumulative temperature deficit/frequency of occurrence of cold days), respectively, are also calculated for each station.

In order to study the time evolution of all the above indices within the entire Greek area, the regional average indices are 
calculated for the warm and cold period. The term "regional" is used to denote that these indices include the entire Greek territory, while the term "regional average" is used because the new regional indices are the average values of the $17 \mathrm{re}-$ spective indices resulted from all the studied stations. To create the regional indices, the time series of all indices, for all stations and for all studied periods (warm and cold) were first standardized. The standardized anomalies from all the stations were averaged per year, giving the annual regional average indices. Frich et al. (2002) used the same method to produce averaged global indicators, and investigated the climatic extremes severity and frequency changed throughout the second half of the 20th century. In addition, in order to study the decadal (10 years) evolution of the same indices for the Greek area, the annual standardized anomalies were added per decade (for every station) and then, the sums were averaged creating the anomalies of the decadal regional averaged indices. Although the above indices somehow ignore the physiological local differentiation of the studied stations, nevertheless, they are good regional measures for the general trend of the examined indices.

In particular, the following regional indices were calculated per decade over the chronological period of 1961-2000 for the warm and cold periods: (1) frequency of warm days, (2) frequency of cold days, (3) cumulative temperature surplus for warm days, (4) cumulative temperature deficit for cold days, (5) cumulative temperature rest, (6) surwar and (7) defcol.

\section{Results}

\subsection{Warm and cold days}

From the study of the decadal regional averages of the frequencies of occurrences of warm (raf_WD) and cold (raf_CD) days, it can be noted that for the warm period (Fig. 2a), raf_CD positive anomalies and raf_WD negative anomalies are observed, during the period 1971-1990. In contrast, positive anomalies are recorded for the raf_WD and negative for the raf_CD, during the first and the last decade. From the beginning of the examined period, the two indices follow an opposite course, namely the raf_WD follow a negative and the raf_CD a positive trend till the middle of the 70 's, where the courses of both indices were reversed. In the decade of the 90's, raf_WD with positive anomalies and raf_CD with negative anomalies are encountered.

In the cold period (Fig. 2b), the maximum positive anomalies for the raf_WD are depicted in the 60's and especially in the first half of the 60's. In the next decades, only negative anomalies are recorded, following a rather positive trend till the end of the 90's. The anomalies of the raf_CD are negative till the mid 70's, where this situation changed, and positive anomalies appeared following a rather negative trend till the end of the 90's.

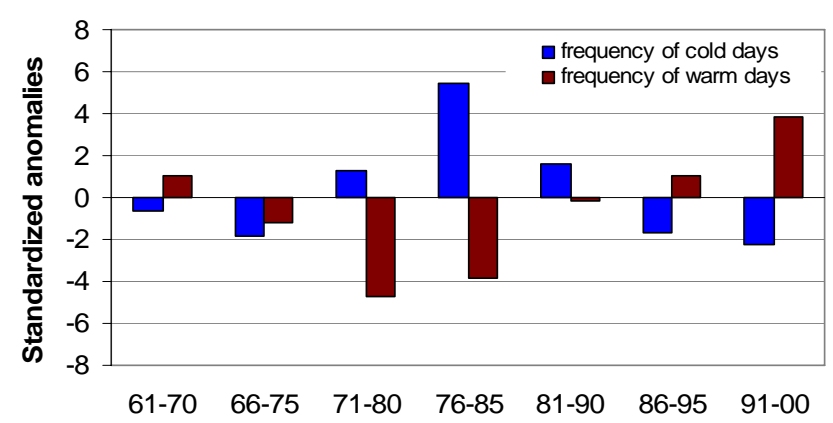

(a) Warm period

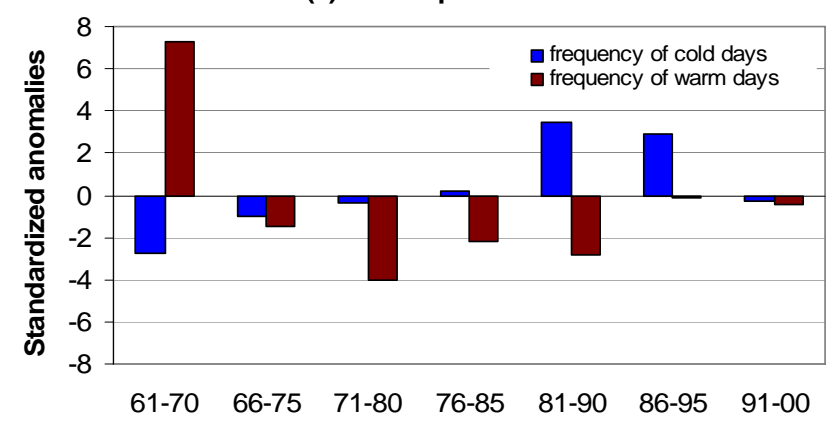

(b) Cold period

Fig. 2. Decadal regional averages of the frequencies of occurrences of warm (raf_WD) and cold (raf_CD) days for the warm (a) and cold (b) period.

In general, it can be argued that the 70's and 80's was a period of many cold temperature extremes, something that was reversed in the next decades. Although in the same 20-year period, warm days were fewer than those that Greece had experienced previously, in the 90's they were increased, reaching their second maximum. It is noteworthy, that the decade 1961-1970 presents the maximum of the frequencies of occurrences of the warm days in the cold period, something that significantly contributes to the respectively yearly maximum. After the 70's, during the warm and cold periods, the warm days increased and cold days decreased. Finally, cold period emerges with a decadal delay from the warm period with respect to the maximum of the frequencies of occurrences of cold days.

\subsection{Cumulative temperature surplus and deficit}

The decadal regional average of the cumulative temperature surplus (ract_S) and deficit (ract_D) indices for the warm and cold period are presented in Fig. 3a, b. The illustration for the warm period (Fig. 3a) shows positive anomalies for the ract_S from the 80 's till the end of the studied period, and negative anomalies for the ract_D, except for the period 1976-1990.

In the cold period (Fig. 3b), the ract_S anomalies are negative for almost all the studied period, except for the decade 1961-1970. The anomalies for the ract_D are negative till 


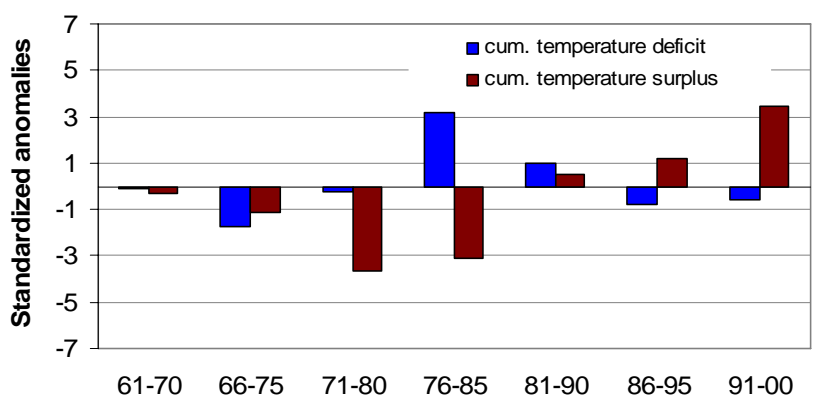

(a) Warm period

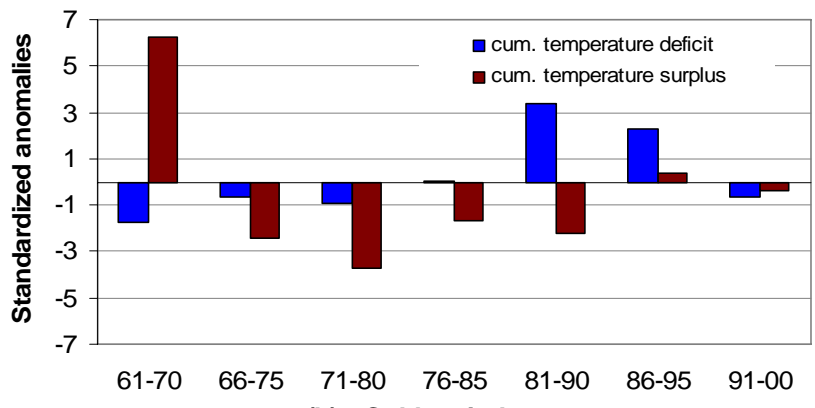

(b) Cold period

Fig. 3. Decadal regional averages of the cumulative temperature surplus and deficit of warm (ract_S) and cold (ract_D) days, for the warm (a) and cold (b) period.

1980 , and present a maximum positive anomaly in the decade of the 80 's, ending up with negative anomalies during the last decade.

\subsection{Cumulative temperature rest}

The cumulative temperature rest, as stated above, is the difference of the cumulative deficit from the cumulative surplus and is an overall interdecadal index, showing the temperature cooling or warming, per decade. Figure $4 \mathrm{a}$, b illustrates the warm and cold period courses of the regional average cumulative temperature rest (ract_rest) anomalies per decade. These results are in effect for the inter-decadal courses of all the indices that were studied before, something that is obvious from the corresponding diagrams. In the warm period, (Fig. 4a), negative anomalies dominated in the middle of the studied period (1971-1985) and positive in the last two decades. During the other decades, ract_rest is near zero, indicating that it follows the mean conditions. In Fig. $4 \mathrm{~b}$, which shows the anomalies in the cold period, it can be noted that they have a positive sign in the first and also in the last decade. The minimum, in the warm and cold period, is observed in the decade of 70's and 80's, respectively. After that minimum, in both periods, there is a steady increase till the end of the 90's, where the anomalies become positive again. Combining Fig. 4a and $\mathrm{b}$ it can be stated that a cooling (negative rest) starts in the middle 60's, maximizes in the mid 70's, tops in the mid 80's and falls around zero almost in the end

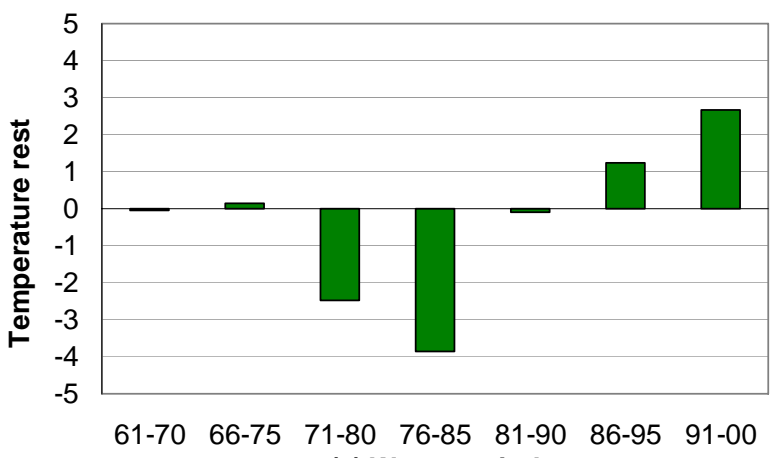

(a) Warm period

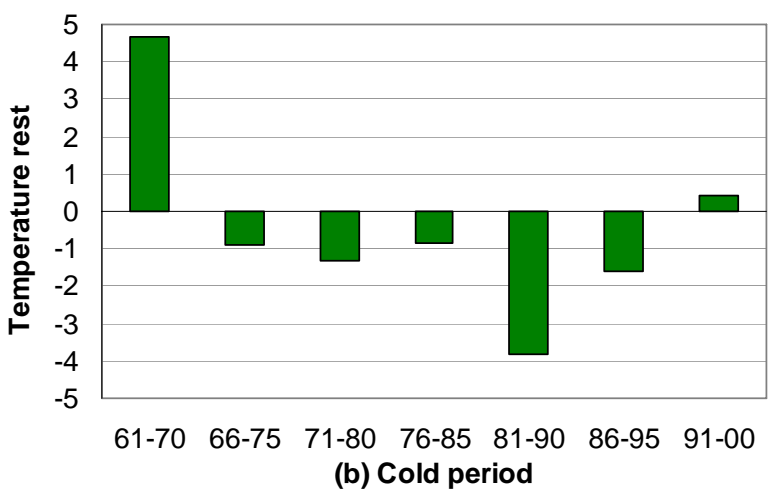

Fig. 4. Decadal regional averages of the cumulative temperature rest (ract_rest) for the warm (a) and cold (b) period.

of the 80's. After this cooling, there is a warming (positive rest) in the 90's, and so on.

The decadal regional temperature rest follows the basic features of the temperature time series course through the studied period. Specifically, on the warm period basis, the values of this index reflect the cooling till the mid of the 80's, and warming till the end of the 90's. These were shown by many earlier studies (Proedrou et al., 1997; Giles and Flocas, 1984) for the Greek region. Maheras et al. (2006) attributed the positive temperature trend in summer to the increase of the frequency of the anticyclonic types in Greece. In the cold period, a minimum is observed in the decade of the 80's, and the overall trend is negative, despite the slight positive trend in the last decades. This negative trend in the temperature rest in the cold period of the year is also in agreement with the negative trend in winter temperatures in Greece (Luterbacher et al., 2000; IPCC, 1996). According to Feidas et al. (2004) the general cooling trend in Greece is associated with the positive phases of the Mediterranean Oscillation Index (MOI) and the Mediterranean Circulation index (MCI). In general, Greece experienced rather a slight negative temperature trend in the 20th century (IPCC, 1996; Feidas et al., 2004). Notwithstanding this, a warm period began from the mid 90's following overdue, the earlier warming trend in the North Hemisphere. 


\subsection{Defcol and surwar}

Figure $5 \mathrm{a}, \mathrm{b}$ displays the inter-decadal courses of the regional average indices of Surwar (ra_Surwar) and Defcol (ra_Defcol). These two indices, as noted before, are a measure of the intensity of the warm and cold days, respectively. In the warm period (Fig. 5a), it is worth mentioning that from mid 80 's, the anomalies of ra_Surwar are negative and the anomalies of ra_Defcol positive, something that leads to the conclusion that cold days are more intense than warm days.

The situation in the cold period (Fig. 5b) is more complex and variable. Although the anomalies for the ra_Surwar are mostly positive, in the period 1966-1980 are negative. The standardized anomalies for the ra_Defcol are positive in the decade 1961-1970, nearing zero in intermediate decades and being negative in the last 15 years.

\section{Discussion and conclusion}

Based on the aforementioned and relying upon a comparative study, the following can be stated for the warm and cold periods:

Warm period: In the 70's and 80's, the cold days are more than the warm days, but the opposite results have been proved valid for their intensity. The above, leads to the conclusion that, although more extreme cold days than warm are recorded in this period, the extreme warm days are more intense. After 1981, the frequencies of occurrences and the temperature surplus of the extreme warm days increase, but their intensity decrease. This implies that Greece experienced more extreme warm days, though not as extreme as in the past. With respect to the cold days, in spite of the fact that they decrease after 1981, their intensity follows rather an increasing trend. Kostopoulou and Jones (2005) studied climate extreme indices in the Eastern Mediterranean and revealed a significant positive trend in both minimum and maximum temperature extremes.

The increased maximum temperature in summer is associated with a slight increase in the anticyclonic circulation types in summer (Maheras et al., 2000, 2006), which are connected with a westerly and southwesterly flow that brings warm air masses from Northern Africa to Greece (Maheras et al., 2006). Furthermore, a positive pressure trend in eastern and southeastern Mediterranean results in less frequent low-pressure fields, resulting in less frequent Etesian winds flow and therefore higher temperatures (Feidas et al., 2004). Xoplaki et al. (2005) associate warm summers of the last 50 years in the Mediterranean region with blocking conditions, subsidence and stability.

Cold period: From the middle of the 60's to the end of the 90 's, a negative temperature rest is recorded. Throughout all decades, the cold days are numerically more than the warm days. However, this situation tends to change, especially after the mid 80 's, when the frequency of the warm days gradually increased and the frequency of cold

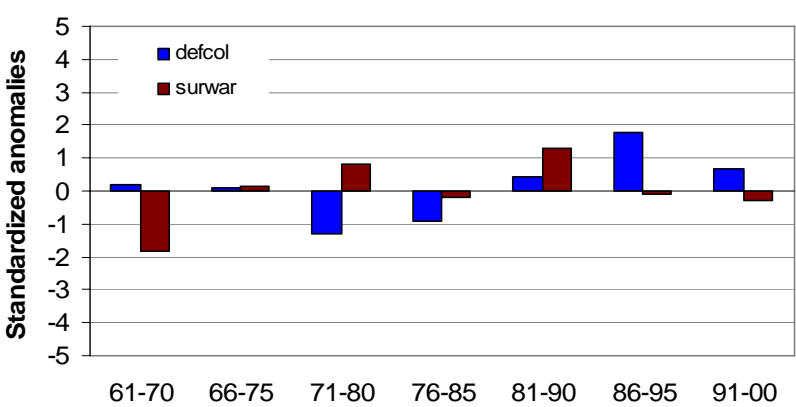

(a) Warm period

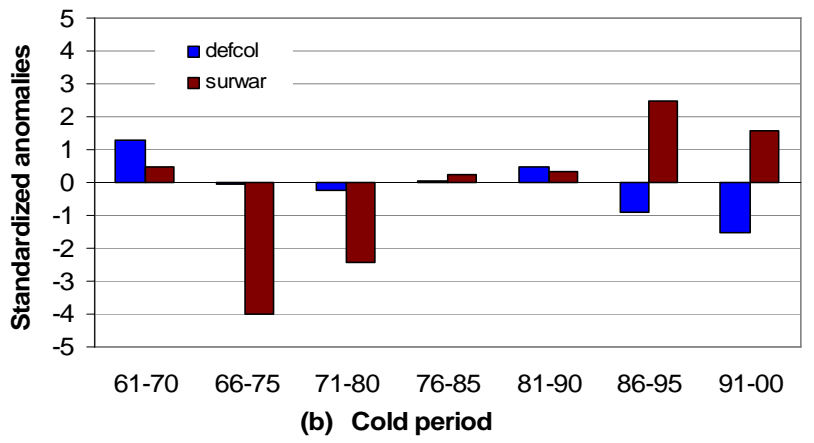

Fig. 5. Decadal regional averages of cumulative temperature surplus divide by the frequency of warm days (ra_ Surwar) and cumulative temperature deficit divide by the frequency of cold days ( $\mathrm{ra}_{-}$ Defcol), for the warm (a) and cold (b) period.

days decreased. The above are followed up by a decrease in the intensity of the cold days and a slight increase in the intensity of the warm days. For the same period, Maheras et al. (2006) found that winter minimum and maximum temperature analyses present a negative trend, though non significant, in all regions of Greece. In the present study the decadal frequency of the warm days present a negative trend through the period 1961-2000, something that is coincided with the previous study, but the decadal frequency of cold days follow slightly positive trend. Over and above, it is worth to mention that the regional temperature rest presents a negative trend, something corresponding with a cooling trend in the cold period. Perhaps, the above differences are due to the different study periods (cold period and winter) and also to the different indices used in the two studies. Feidas et al. (2004) consider that the cooling trend in the winter minimum temperature is associated with a northerly component to the flow into Greece from the north Eurasia, something that is associated with an increase in the frequency and persistence of anticyclones that influence Greek area (Maheras et al., 2000). In Europe, the recent warming trend (1976-1999) is attributed to a positive trend in the number of warm-spell days during the cold period of the year (Tank et al., 2002).

Edited by: S. C. Michaelides

Reviewed by: two anonymous referees 


\section{References}

Alexander, L. V., Zhang, X., Peterson, T. C., Caesar, J., Gleason, B., Tank, K., Haylock, M., Collins, D., Trewin, B., Rahimzadeh, F., Tagipour, A., Rupa Kumar, K., Revadekar, J., Griffiths, G., Vincent, L., Stephenson, D. B., Burn, J., Aguilar, E., Brunet, M., Taylor, M., New, M., Zhai, P., Rusticucci, M., and VazquezAguirre, J. L.: Global observed changes in daily climate extremes of temperature and precipitation, J. Geophys. Res., 111, D05109, doi:10.1029/2005JD006290, 2006.

Alexanderson, H.: A homogeneity test applied to precipitation data, J. Climatol., 6, 661-675, 1986.

Burgueno, A., Lana, X., and Serra, C.: Significant hot and cold events at the Fabra Observatory, Barcelona (NE Spain), Theor. Appl. Climatol. 71, 141-156, 2002.

Cartalis, C., Chrysoulakis, N., Feidas, H., and Pitsitakis, N.: Categorization of cold period weather types in Greece on the basis of the photointerpretation of NOAA/AVHRR imagery, Int. J. Remote Sens., 25, 2951-2977, 2004.

Chan, K., Mysterud, A., Øritsland, N., Severinsen, T., and Stenseth, N.: Continuous and discrete extreme climatic events affecting thw dynamics of a high-arctic reindeer population, Oecologia, 145, 556-563, 2005

Chagnon, S. A.: Measures of economic impacts of weather extremes, B. Am. Meteorol. Soc., 84, 1231-1235, 2003.

Della-Marta, P. M., Haylock, M. R., Luterbacher, J., and Wanner, H.: Doubled length of western European summer heat waves since 1880, J. Geophys. Res., 112, D151103, doi:10.1029/2007JD008510, 2007a.

Feidas, H., Makrogiannis, T., and Bora-Senta, E.: Trend analysis of air temperature time series in Greece and their relationship with circulation using surface and satellite data: 1955-2001, Theor. Appl. Climatol., 79, 185-208, 2004.

Frich, P., Alexander, L. V., Della-Marta, P., Gleason, B., Haylock, M., Klein Tank, A. M. G., and Peterson, T.: Observed coherent changes in climatic extremes during the second half of the twentieth century, Climate Res., 19, 193-212, 2002.

Giles, B. D. and Flocas, A. A.: Air temperature variations in Greece, Part 1. Persistence, trend, and fluctuations, Int. J. Climatol., 4, 531-539, 1984

IPCC, Climate Change 1995: The science of Climate Change: Contribution of Working Group I to the second Assessment Report of the Intergovernmental Panel on Climate, Cambridge: Cambridge University Press, 1996.
Kostopoulou, E. and Jones, P. D.: Assesment of climate extremes in the Eastern Mediterranean, Meteorol. Atmos. Phys., 89, 69-85, 2005.

Luterbacher, J., Xoplaki, E., Burgard, R., and Schmutz, C.: Connection between the large scale lower atmospheric circulation and the winter temperature variability over Greece: 1957-1997. Proc. 5th Greek Scientific Conference in Meteorology-ClimatologyAtmospheric Physics, Thessaloniki, 28-30 September 2000, 8188, 2000.

Maheras, P., Patrikas, I., Karacostas, T., and Anagnostopoulou, C.: Automatic classification of circulation types in Greece: methodology, description, frequency, variability and trend analysis, Theor. Appl. Climatol., 67, 205-223, 2000.

Maheras, P., Flokas, H., Tolika, K., Anagnostopoulou, C., and Vafiadis, M.: Circulation types and extreme temperature changes in Greece, Climate Res., 30, 161-174, 2006.

Mazarakis, N., Kotroni, V., Lagouvardos, K., and Argiriou, A.: Storms and lightning activity in Greece during the warm periods of 2003-2006, J. Appl. Meteorol. Clim., 47, 3089-3098, 2008.

Moberg, A. and Jones, P. H.: Trends in indices for extremes in daily temperature and precipitation in central and western Europe, 1901-1999, Int. J. Climatol., 25, 1149-1171, 2005.

Proedrou, M., Theoharatos, G., and Cartalis, C.: Variations and trends in annual and seasonal air temperature in Greece determined from ground and satellite measurements, Theor. Appl. Climatol., 57, 65-78, 1997.

Rusticucci, M., and Vargas, W.: Cold and warm events over Argentina and their relationship with the ENSO phases: risk evaluation analysis, Int. J. Climatol., 22, 467-483, 2002.

Tank, K. and Können, G. P.: Trends in indices of daily temperature and precipitation extremes in Europe, 1946-1999, J. Climate, 16, 3665-3680, 2003.

Tank, K., Wungaard, J. B., Koennen, G. P. and co-authors: Daily dataset of 20th-century air temperature and precipitation series for the European climate assessment, Int. J. Climatol., 22, 14411456, 2002.

Xoplaki, E., Luterbacher, J., and Gonzalez-Rouco, J. F.: Mediterranean summer temperature and winter precipitation, large-scale dynamics, trends, Il Nuovo Cimento, 29(1), doi:10.1393/ncc/i2005-10220-4, 2005. 